\title{
Optimal selling price, replenishment cycle and payment time among advance, cash, and credit payments from the seller's perspective
}

\author{
Lin Feng ${ }^{1} \cdot$ Konstantina Skouri ${ }^{2} \cdot$ Wan-Chih Wang ${ }^{3} \cdot$ Jinn-Tsair Teng $^{4,5}$ (D) \\ Published online: 25 August 2020 \\ (c) Springer Science+Business Media, LLC, part of Springer Nature 2020
}

\begin{abstract}
Although research on pricing and lot-sizing decisions concerning payment types has been extensive, almost all of it has been done from the buyer's perspective. In this study, we incorporate the following relevant and essential facts. If a seller allows a buyer to pay on credit, it increases sales volume. But if a seller asks a buyer for an advance payment, it decreases sales volume. Sometimes, a seller offers a buyer a price discount for an advance payment to increase sales and profitability. Asking a buyer for an advance payment bears interest earned and has no default risk. If a seller offers a buyer the opportunity to pay on credit, then a longer credit period may mean a higher the sales volume, but the default risk is higher, too. The seller wants to set an optimal selling price, replenishment time, and payment method simultaneously so that the profit per unit time is maximized. To achieve this, we develop and compare the seller's profit per unit time under each of three payment methods - advance, cash and credit. Through numerical analyses, the following managerial insights are highlighted: (1) Under certain conditions, a specific payment type obtains the seller's highest profit among all three payment types. (2) If advance payment is required, then it is critically important for a seller to offer a price discount. (3) An advance payment generates more profit than a credit payment provided that sales volume from a credit payment to an advance payment declines insignificantly and vice versa.
\end{abstract}

Keywords Pricing $\cdot$ Payment timing $\cdot$ EOQ $\cdot$ Advance payments $\cdot$ Credit payments

\section{Introduction}

The key target of the retail industry used to be to receive payment immediately after delivering a product, either with a cash-on-delivery or cash payment. However, recent studies indicate that $90 \%$ of buyers from the United States prefer a short-term, interest-free credit payment, that is, buy now and pay later. Normally, there are no interest charges if a buyer pays in full within the credit period. However, if the buyer fails to do so, the seller can charge interest on the outstanding balance.

Jinn-Tsair Teng
tengj@wpunj.edu

Extended author information available on the last page of the article 
As opposed to a cash payment, giving buyers a credit payment lowers the buyer's holding cost, and thus increases the seller's sales volume. However, from a seller's perspective, the main problem with credit payment is that the seller may not be able to collect all of the money from some default customers. Furthermore, the seller loses interest incomes during the credit period. To control default risks, interest losses, and cancellations of orders, the seller might prefer to get paid in advance. In that payment method, the seller would demand that the buyer pay for goods and services before the time of delivery.

An advance payment might bring several benefits to a seller. The probability for default risk is zero. There would be no order cancellations. The seller could earn some interest from prepayments. However, if a seller asks a buyer for an advance payment, it increases the buyer's cost, and hence decreases sales volume. On the other hand, from a seller's perspective, offering a credit payment increases not only sales volume but also the default risk and the opportunity cost, meaning interest lost during the credit period.

A seller wants to maximize profit as much as possible, so it is a constant challenge to decide optimal payment type-advance, cash or credit.

Based on economics and marketing theory, if the price of goods or services goes down, then the demand for the product should increase. That makes price one of the most important factors to influence sales and profitability.

When selling goods or services, today's companies can use a variety of pricing strategies to increase sales and profitability. It's up to the seller to determine the optimal selling price. For example, when selling unique goods or services, the seller may use a premium pricing and set its price higher than its competitors do. Another method to attract buyers would be to adopt penetration pricing, putting a lower price on goods and services.

To maximize profitability on new products and services, a company could offer price skimming and set a higher price during the introductory phase and then gradually lower the price when competing goods or services appear on the market. A small company could bundle multiple products, then set a lower price than consumers would pay if they purchased each item individually.

In the inventory literature, almost all models are developed from the buyer's perspective in order to obtain the optimal order quantity under various payment types. Inventory models with various payment terms explored from the seller's perspective to obtain the optimal solution for the seller are rare in the literature.

In addition, the law of demand states that, for nearly all products, the higher the price the lower the demand. However, higher prices can also mean higher profits. Hence, pricing is one of the most important business decisions that management makes.

In this paper, we first study pricing, lot-sizing, and payment-timing decisions in a joint finance, marketing, and operation model. This captures the following relevant facts:

1. Granting a credit payment to buyers, who consider it as a type of price reduction, increases sales volume. Asking buyers for an advance payment can decrease sales volume;

2. Asking buyers for an advance payment can earn interest earned for the seller and has no default risk;

3. Offering buyers, a credit payment can mean that the seller's sales volume will increase, but so will the default risk; and

4. Offering buyers price discounts for an advance payment can increase sales and profitability for the seller.

The goal for the seller is to determine the optimal selling price, replenishment time and payment term simultaneously to maximize the profit per unit time.

The purpose of this study is to answer the following major questions: 
a. Which payment option generates the highest total profit and/or the lowest selling price for the seller, when the demand rate is a multiplicative function of the selling price and the payment time?

b. Is the total profit significantly improved if the seller offers a price discount when asking for advance payment?

c. What is the impact of default risk on the seller's optimal selling price and total profit if the seller grants a downstream credit payment?

Hence, the main contribution of the study is to introduce new and important managerial insights to the field of pricing strategies from the seller's perspective under three distinct and well-established payment methods-advance, cash and credit.

The remainder of this paper is organized in the following sections: Sect. 2 reviews the relative literature. Section 3 presents the problem definition and basic assumptions. Section 4 develops a mathematical model for the proposed study. Section 5 finds the optimal solution to the defined problem. Section 6 tests the numerical validity of the model. Section 7 concludes with a discussion of the major findings of the present study.

\section{Literature review}

There is a vast amount of literature for inventory models with credit payments. The first review of inventory models under trade credits was given by Chang et al. (2008). A second, more recent review was provided by Seifert et al. (2013). In this paper, only those closely related to our proposed model will be mentioned.

For trade credit financing, Hwang and Shinn (1997) investigated the joint determination of price and lot size for an exponentially deteriorating product when the supplier permits delay in payments.

Teng et al. (2005), by assuming that the selling price is necessarily higher than the purchase cost, studied an economic order quantity (EOQ) model to determine the retailer's optimal price and lot size simultaneously when the supplier offers a permissible delay in payments.

Teng et al. (2006) further extended the EOQ model to an economic production quantity (EPQ) model. Ho et al. (2008) developed an integrated supplier-retailer inventory model in which the demand is sensitive to the retail price. Also, the supplier offers a two-part trade credit policy offering cash discount and delayed payment. If the retailer pays off the purchased items within a certain number of days, he will receive a cash discount; otherwise, the full purchasing cost must be paid between a certain number of days to the final payment.

Ouyang et al. (2009) explored an integrated EOQ model to jointly determine the retailer's order quantity and the supplier's production batch in order to maximize the total profit.

Chang et al. (2009) proposed a trade credit linked to the order quantity in which the buyer receives an interest-free credit period if the buyer's order quantity exceeds or equals a predetermined quantity; if it does not, the buyer must pay for the items immediately upon delivery.

Thangam and Uthayakumar (2010) derived optimal pricing and lot-sizing policies for perishable items with two warehouses, when the seller grants buyers a partial trade credit policy. The policy requires that a portion of the purchase amount to be paid on delivery, and the remainder of the purchase amount to be paid in credit.

Jaggi et al. (2014) developed a retailer's optimal ordering and pricing decisions for deteriorating items in a two-warehouse environment, in which shortages are fully backordered. 
Chang et al. (2015) investigated optimal pricing and ordering policies for items that don't instantly deteriorate when trade credit is linked to order quantity.

Mahata (2015) proposed a pricing and lot-sizing model for deteriorating and ameliorating items under two levels of trade credit policy. In this model, the retailer receives a full trade credit from the supplier while offering a partial trade credit to customers.

Tsao et al. (2017) explored an inventory model for non-instantaneously deteriorating items for which the selling prices differ in the non-deteriorating and deteriorating periods.

Tiwari et al. (2018) expanded the previous model studied by Mishra et al. (2018) under permissible delay in payments. This allows for partial backlogging and upstream and downstream partial trade credits.

$\mathrm{Li}$ and Teng (2018) studied pricing and lot-sizing policies for perishable items when demand depends on selling price, reference price, product freshness, and displayed stocks.

Thereafter, Feng and Chan (2019) derived joint pricing and production decisions for new products, with learning curve effects, under upstream and downstream trade credits.

At the same time, Li et al. (2019a) studied optimal pricing, lot-sizing and backordering decisions when a seller demands an advance-cash-credit payment scheme. The buyer prepays a fraction of the total purchase cost when placing an order, then pays another fraction of the total purchase cost, in cash, upon receiving the order quantity. The buyer then receives a short-term, interest-free credit payment for the remainder of the total purchase cost.

Recently, Taleizadeh et al. (2019) developed an inventory model with probabilistic replenishment intervals and partial backordering under permissible delay in payments.

To obtain the optimal replenishment time and credit period for the seller, Teng and Lou (2012) incorporated the fact that trade credit has a positive impact on demand.

Wang et al. (2014) further generalized the model to allow for deteriorating products that have maximum shelf life.

When the seller offers buyers a credit payment, Chen and Teng (2015) obtained inventory and credit decisions for deteriorating items with upstream and downstream trade credit financing. The longer the credit period, the higher the sales volume, as well as the higher the default risk.

Recently, Li et al. (2019b) explored optimal selling price, credit period, and order quantity simultaneously for perishable goods when demand depends on three things: selling price, expiration date and credit period.

As to advance payments, in order to obtain the ordering quantity and price to maximize the expected profit, Maiti et al. (2009) studied an inventory model with advance payments, stochastic lead-time and price-dependent demand. They used a generalized, reduced-gradient technique and a stochastic search genetic algorithm.

Thangam (2012) established optimal pricing and lot-sizing policies for perishable items. They used an advance-payment scheme in a supply chain in which the retailer receives an upstream trade credit from the supplier, while granting a downstream trade credit to customers.

Taleizadeh (2014) examined the circumstance that a gasoline supplier asks a gas station to prepay a portion of the purchase cost upfront when placing an order and then to pay the remainder in cash on delivery.

Lashgari et al. (2016) built an EOQ model with upstream partial advance payment and downstream partial credit payment with or without shortages.

Teng et al. (2016) explored an economic order quantity model for deteriorating items, with advance payments. In their model, the deterioration rate of a product gradually increased as the expiration date approached. 
Li et al. (2017) considered joint pricing and inventory decisions for perishable products under trade credit. They assumed that the demand is influenced by the combined effect of selling price and product freshness when the seller asks the buyer for an advance-cash-credit payment.

Concurrently, Tavakoli and Taleizadeh (2017) examined a buyer's EOQ model for a decaying item with a full prepayment method.

Taleizadeh et al. (2018) further investigate the customer's inventory policy by considering two different scenarios: full prepayment with shortage and partial prepayment-partial delayed payment with shortage.

Li et al. (2018) also proposed an inventory model to determine the jointly optimal ordering quantity and the best payment terms, their choices being advance, cash and credit. This model then determined the optimal payment period to maximize the seller's profit.

Chang et al. (2019) investigated optimal pricing and lot-sizing decisions for perishable products when the supplier demands that the manufacturer use a combination of advance, cash, and credit payments for the total purchase cost.

Currently, Taleizadeh et al. (2020) proposed an EOQ model with mixed sales when the payment scheme is mixed with multiple advance payment and partial credit payment.

All of these papers can be classified into the account of the payment policy; the demand function; the member of the supply chain who is applicable to the model; and the decision variables. This classification is presented in Table 1.

\section{Problem description}

We use the following notation and assumptions in the model's development. For simplicity, we define the following symbols, then place them in alphabetical order.

\begin{tabular}{ll}
\hline$C$ & Purchasing cost per unit, in dollars \\
$d_{1}$ & Coefficient of price discount, $d_{1} \geq 0$ \\
$d_{2}$ & Coefficient of default risk on revenue, $d_{2} \geq 0$ \\
$H$ & Holding cost per unit per unit time including interest charged, in dollars, $h \geq r P$ \\
$L$ & Payment period, in unit time (a decision variable) \\
$O$ & Ordering cost per order, in dollars \\
$P$ & Selling price per unit, in dollars (a decision variable) \\
$R$ & Interest rate per dollar per unit time \\
$T$ & Replenishment cycle time, in unit time (a decision variable) \\
$*$ & Superscript representing an optimal value \\
\hline
\end{tabular}

The mathematical model with advance, cash, and credit payments is developed under the following assumptions:

Price is an important factor in a consumer's purchasing decision. According to traditional marketing and economic theory, the higher the price, the lower the demand. Hence, demand function is a downward-slope function of the price. By following Robinson and Lakhani (1975), Thompson and Teng (1984), Feng et al. (2017), and Li et al. (2017). The demand rate $D$ is considered as proportional to an exponential function of the price $P$. Thus, one can have

$$
D \approx e^{-\lambda P}, \lambda>0
$$




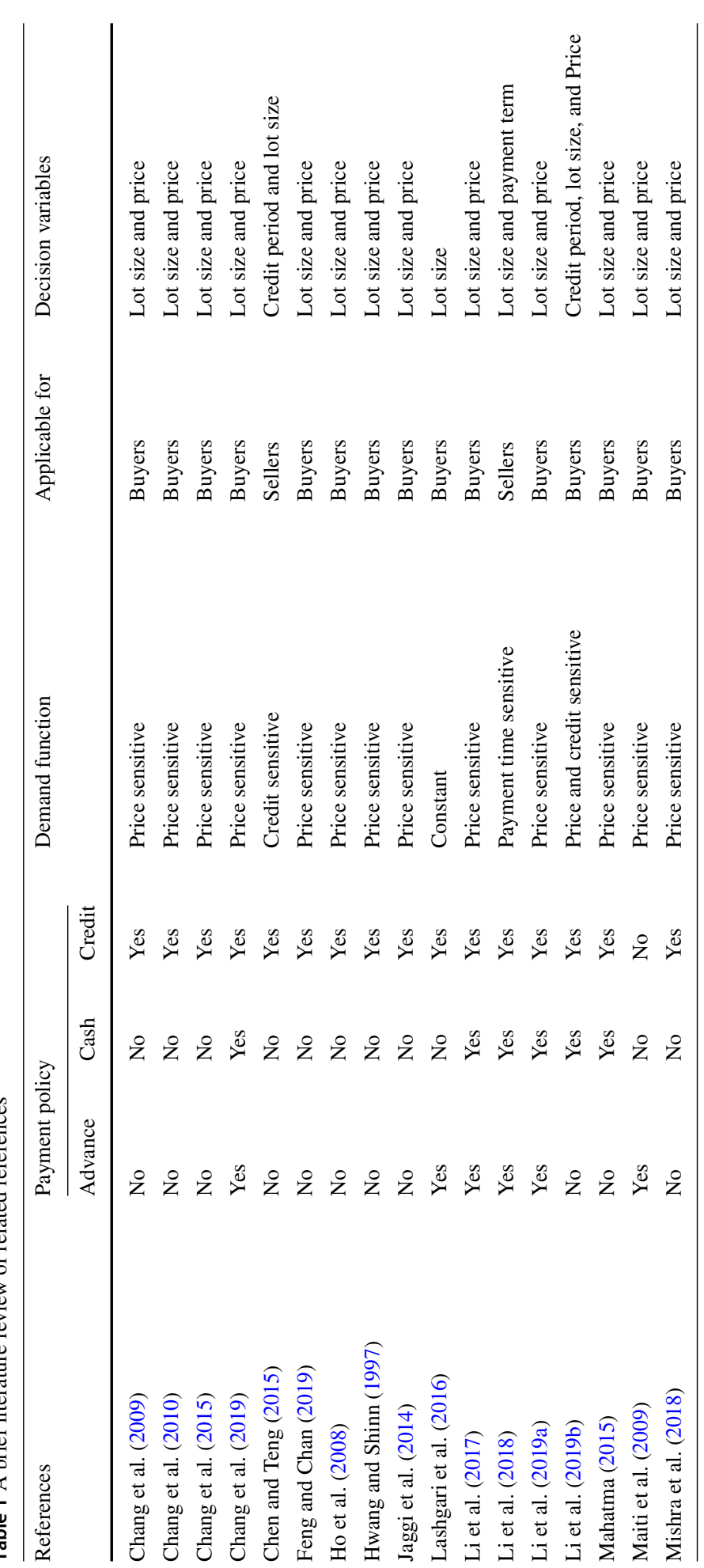

\section{包 Springer}




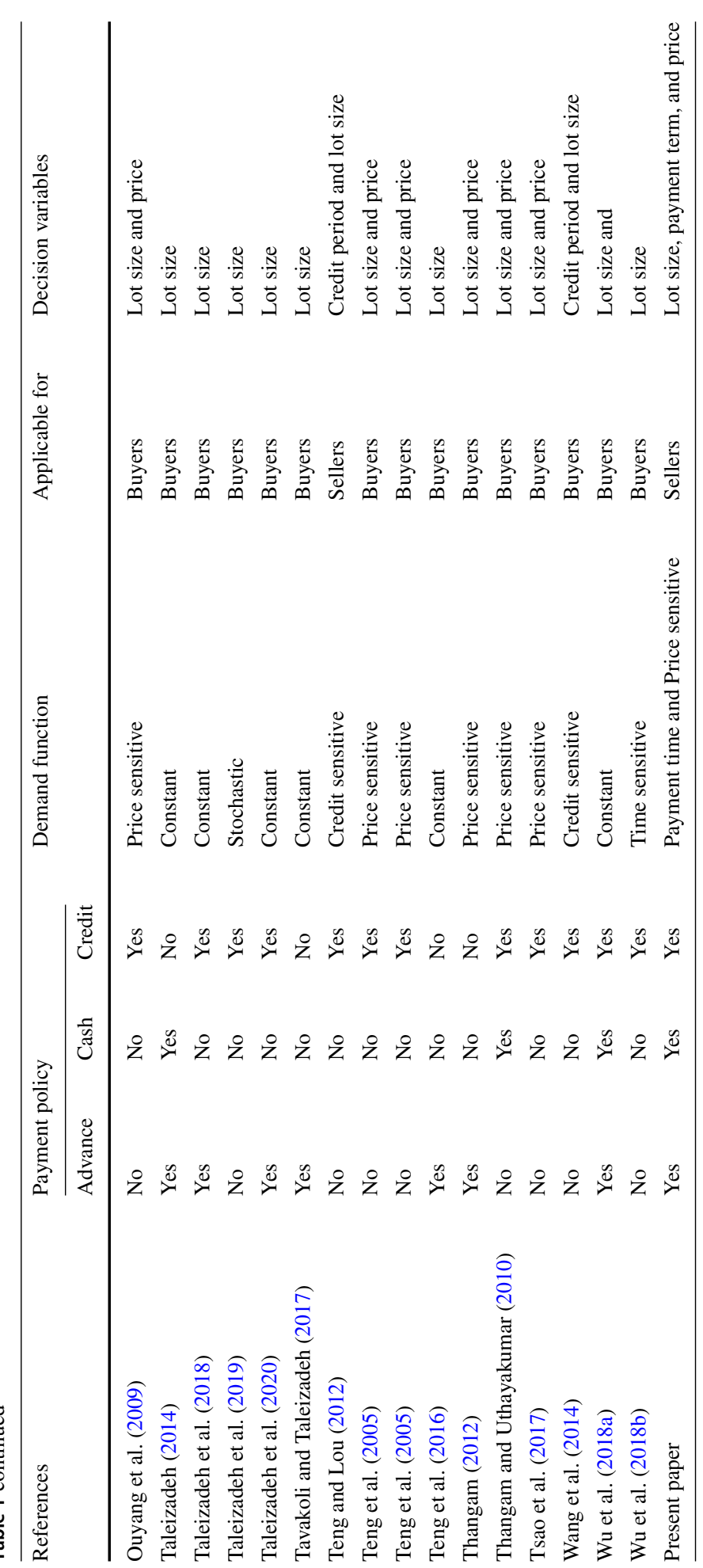


It is observed as in Jaggi et al. (2008) that trade credit offered by the seller to customers has a positive impact on demand. In fact, the longer the trade credit, the higher the demand. Conversely, the earlier the advance payment, the less the demand. As a result, demand rate is an upward-slope function of the payment time $L$. By following Teng and Lou (2012), and Chen and Teng (2015), the demand rate $D$ is also considered as an exponential function of the payment time $L$. That is,

$$
D \approx e^{\alpha L}, \alpha>0
$$

Combining (1) and (2), the demand rate $D$ is a multiplicative function of the payment time $L$ and the unit price $P$ can be obtained as:

$$
D=D(L, P)= \begin{cases}K e^{\alpha_{1} L-\lambda P}, & \text { if } L \leq 0 \\ K e^{\alpha_{2} L-\lambda P}, & \text { if } L \geq 0 .\end{cases}
$$

where $K$ is a positive constant, the payment time $L<0$ stands for an advance payment with the coefficient $\alpha_{1}>0$, while $L=0$ is a cash payment on delivery, and $L>0$ represents a credit payment with the coefficient $\alpha_{2}\left(>d_{2}\right)$.

Granting a credit payment to customers, that is, a short-term interest-free loan, stimulates more sales than asking for an advance payment, shown as a short-term, interest-earned prepayment from customers. The longer the prepayment period for an advance payment, the lower the sales volume but the higher the interest earned.To prevent low sales volume, a seller usually offers a price discount (e.g., $\left.\left(1+d_{1} L\right) P\right)$ to customers when asking for an advance payment (e.g., $L<0)$. The earlier the prepayment period, the higher the price discount. As a result, the revenue received during the replenishment cycle time $T$ is

$$
\left(1+d_{1} L\right) P D T=\left(1+d_{1} L\right) P K e^{\alpha_{1} L-\lambda\left(1+d_{1} L\right) P} T=\left(1+d_{1} L\right) P T K e^{\left(\alpha_{1}-\lambda d_{1} P\right) L-\lambda P} .
$$

For simplicity, we assume that the negative effect of an advance payment on demand $\alpha_{1}$ is greater than or equal to the positive effect of price discount on demand $\lambda d_{1} P$ (i.e., $\alpha_{1} \geq \lambda d_{1} P$ ). Otherwise, the seller would not ask customers for an advance payment.

A 30-year mortgage has a higher default risk than a 15-year mortgage. Likewise, the longer the credit period is, the higher the percentage that the buyer will not be able to pay off the debt. So, the longer the credit period, the higher the default risk. By following Chern et al. (2013, 2014), Wang et al. (2014), and Chen and Teng (2015), we assume that the rate of default risk given credit period $L$ can be taken as follows:

$$
R(L)=1-e^{-d_{2} L},
$$

where $d_{2}$ is zero or a positive constant. Notice that the default risk is zero if it is a cash on delivery (i.e., $R(0)=0$ ). On the other hand, the default risk is $100 \%$ if the payment time $L \rightarrow \infty$ (i.e., $R(\infty)=1$ ). We can assume in general that the positive effect of trade credit on demand $\alpha_{2}$ is greater than the negative effect of default risk on revenue $d_{2}$ (i.e., $\alpha_{2}>d_{2}$ ). Otherwise, the seller would not provide a credit payment to customers.

Given the above notation and assumptions, the seller's aim is to determine selling price $P$, payment time $L$ (which corresponds one of three payment terms: advance payment, cash payment, or credit payment), and replenishment cycle time $T$ such that the profit per unit time is maximized. 


\section{Mathematical model}

Given the above notation and assumptions, we can formulate the seller's profit per unit time with respect to advance, cash, and credit payments. The mathematical model is developed for the advance payment first, then for the credit payment and finally for the cash payment.

For the advance payment (i.e., $L<0)$, the seller offers customers a price discount $\left(1+d_{1} L\right) P$ associated with the prepayment period $L$. The seller's revenue received from sales per cycle time $T$ is $\left(1+d_{1} L\right) P D T=\left(1+d_{1} L\right) P K e^{\alpha_{1} L-\lambda\left(1+d_{1} L\right) P} T$, where $\alpha_{1}-\lambda d_{1} P \geq 0$. Similarly, the purchasing cost per cycle time $T$ is given by $c D T=c K e^{\alpha_{1} L-\lambda\left(1+d_{1} L\right) P} T$. Thus, the inventory holding cost per cycle time $T$ is $\frac{1}{2} h D T^{2}=\frac{1}{2} h K e^{\alpha_{1} L-\lambda\left(1+d_{1} L\right) P} T^{2}$. As the revenue received starts from 0 at time 0 to $\left(1+d_{1} L\right) P D T=\left(1+d_{1} L\right) P K e^{\alpha_{1} L-\lambda\left(1+d_{1} L\right) P} T$ at time $T$, the average revenue is $\frac{1}{2}\left(1+d_{1} L\right) P K e^{\alpha_{1} L-\lambda\left(1+d_{1} L\right) P} T$. Consequently, the interest earned per cycle $T$ is the average revenue times the interest rate (i.e., $r$ ) multiplied by the prepayment period (i.e., $-L$ ). Therefore, the interest earned per cycle $T$ is obtained as follows:

$$
\text { Interest earned }=-\frac{1}{2} r L\left(1+d_{1} L\right) P K e^{\alpha_{1} L-\lambda\left(1+d_{1} L\right) P} T .
$$

In summary, the profit per cycle time $T$ is comprised of the revenue received from sales plus the interest earned minus the total cost including the ordering cost, purchasing cost, holding cost. Hence, the total profit per cycle time $T$ is expressed as follows:

$$
\begin{aligned}
& \left(1+d_{1} L\right) P K e^{\alpha_{1} L-\lambda\left(1+d_{1} L\right) P} T-\frac{1}{2} r L\left(1+d_{1} L\right) P K e^{\alpha_{1} L-\lambda\left(1+d_{1} L\right) P} T \\
& -o-c K e^{\alpha_{1} L-\lambda\left(1+d_{1} L\right) P} T-\frac{1}{2} h K e^{\alpha_{1} L-\lambda\left(1+d_{1} L\right) P} T^{2} .
\end{aligned}
$$

Therefore, the profit per unit time for the advance payment is given by $T P_{1}(L, P, T)=$ The total profit per cycle time $T /$ The cycle time $T$

$$
\begin{aligned}
= & {\left[\left(1+d_{1} L\right) P-c\right] K e^{\alpha_{1} L-\lambda\left(1+d_{1} L\right) P} } \\
& -\frac{1}{2} r L\left(1+d_{1} L\right) P K e^{\alpha_{1} L-\lambda\left(1+d_{1} L\right) P}-\frac{o}{T}-\frac{1}{2} h K e^{\alpha_{1} L-\lambda\left(1+d_{1} L\right) P} T \\
= & K e^{\alpha_{1} L-\lambda\left(1+d_{1} L\right) P}\left[\left(1-\frac{1}{2} r L\right)\left(1+d_{1} L\right) P-c-\frac{1}{2} h T\right]-\frac{o}{T}, L \leq 0 .
\end{aligned}
$$

Next, for the credit payment (i.e., $L \geq 0$ ), the revenue received per cycle time $T$ after default risk is the revenue from sales multiplied by $1-R(L)$ as follows:

$$
P K T e^{\alpha_{2} L-\lambda P}[1-R(L)]=P K T e^{\alpha_{2} L-\lambda P} e^{-d_{2} L}=P K T e^{\left(\alpha_{2}-d_{2}\right) L-\lambda P} .
$$

Note that the positive effect of trade credit on demand $\alpha_{2}$ is greater than the negative effect of default risk on revenue $d_{2}$ (i.e., $\alpha_{2}>d_{2}$ ). Otherwise, the seller would not offer a credit payment to customers. On the other hand, the retailer offers customers a credit period of $L$ units of time. Hence, the interest loss per cycle time $T$ is the average revenue (i.e., $\frac{1}{2} P D T=\frac{1}{2} P K e^{\alpha_{2} L-\lambda P} T$ ) times the interest rate (i.e., $r$ ) multiplied by the credit period (i.e., $L$ ), which is obtained as follows:

$$
\text { Interest loss }=\frac{1}{2} r L P K e^{\alpha_{2} L-\lambda P} T .
$$

Likewise, the total profit after default risk per cycle time $T$ is given as the revenue after default risk minus the total cost, which is consisting of the interest loss, ordering cost, 
purchasing cost and holding cost. Thus, the profit after default risk per cycle time $T$ is as follows:

$$
P K e^{\left(\alpha_{2}-d_{2}\right) L-\lambda P} T-\frac{1}{2} r L P K e^{\alpha_{2} L-\lambda P} T-o-c K e^{\alpha_{2} L-\lambda P} T-\frac{1}{2} h K e^{\alpha_{2} L-\lambda P} T^{2} .
$$

Consequently, the profit per unit time for the credit payment is derived as follows:

$T P_{2}(L, P, T)=$ The total profit after default risk per cycle time $T /$ The cycle time $T$

$$
\begin{aligned}
& =P K e^{\left(\alpha_{2}-d_{2}\right) L-\lambda P}-\frac{1}{2} r L P K e^{\alpha_{2} L-\lambda P}-\frac{o}{T}-c K e^{\alpha_{2} L-\lambda P}-\frac{1}{2} h K e^{\alpha_{2} L-\lambda P} T \\
& =K e^{\alpha_{2} L-\lambda P}\left[P e^{-d_{2} L}-\frac{1}{2} r L P-c-\frac{1}{2} h T\right]-\frac{o}{T}, L \geq 0 .
\end{aligned}
$$

Finally, for the case of cash on delivery, substituting $L=0$ into (7) or (11), and simplifying terms, we obtain

$$
T P_{1}(0, P, T)=T P_{2}(0, P, T)=\left(P-c-\frac{1}{2} h T\right) K e^{-\lambda P}-\frac{o}{T} .
$$

Combining (7), (11), and (12), the total profit per unit time is derived as:

$$
T P(L, P, T)=\left\{\begin{array}{lr}
T P_{1}(L, P, T), & \text { if } L<0 \\
T P_{1}(L, P, T)=T P_{2}(L, P, T), & \text { if } L=0 \\
T P_{2}(L, P, T), & \text { if } L>0
\end{array}\right.
$$

As a result, we know that $T P(L, P, T)$ is continuous on $L, P$, and $T$.

The seller's objective is to obtain the optimal payment time $L$, selling price $P$, and replenishment cycle $T$ among one of the three payment terms — advance, cash or credit—such that the profit per unit time $T P(L, P, T)$ is maximized.

In the next section, the optimal solution is characterizing for advance, cash, and credit payments.

\section{Optimal solution}

In order to find the seller's optimal values for $L, P$, and $T$ among one of three payment terms, the optimization problem $\Pi=\max _{L, P, T} T P(L, P, T)$ is divided into two sub-problems with respect to payment timing $L$ as follows:

\begin{tabular}{cc}
\hline$\Pi_{1}=\max _{L, P, T} T P_{1}(L, P, T)$ & $\Pi_{2}=\max _{L, P, T} T P_{2}(L, P, T)$ \\
$L \leq 0$ & $L \geq 0$
\end{tabular}

If $\left(L_{1}^{*}, P_{1}^{*}, T_{1}^{*}\right)=\arg \max _{L, P, T} T P_{1}(L, P, T) \quad$ and $\quad\left(L_{2}^{*}, P_{2}^{*}, T_{2}^{*}\right)=$ $\arg \max _{L, P, T} T P_{2}(L, P, T)$ then the optimal solution of $\Pi=\max _{L, P, T} T P(L, P, T)$ is given by $\left(L^{*}, P^{*}, T^{*}\right)=\arg \max \left\{\max \left\{T P_{1}\left(L_{1}^{*}, P_{1}^{*}, T_{1}^{*}\right), T P_{2}\left(L_{2}^{*}, P_{2}^{*}, T_{2}^{*}\right)\right\}\right\}$. Consequently, in order to obtain the optimal solution of $\Pi=\max _{L, P, T} T P(L, P, T)$, two sub-problems $\Pi_{1}=\max _{L, P, T} T P_{1}(L, P, T)$ with $L \leq 0$, and $\Pi_{2}=$ $\max _{L, P, T} T P_{2}(L, P, T)$ with $L \geq 0$, respectively have been solved. 


\subsection{The optimal solution to $\Pi_{1}$}

For any given $L \leq 0$, taking the first-order partial derivatives of $T P_{1}(L, P, T)$ in (7) with respect to $P$ and $T$, and simplifying terms, we get

$$
\frac{\partial T P_{1}(L, P, T)}{\partial P}=K\left(1+d_{1} L\right) e^{\alpha_{1} L-\lambda\left(1+d_{1} L\right) P}\left[-\lambda\left(1+d_{1} L\right)\left(1-\frac{1}{2} r L\right) P+\lambda\left(c+\frac{1}{2} h T\right)+1-\frac{1}{2} r L\right],
$$

and

$$
\frac{\partial T P_{1}(L, P, T)}{\partial T}=\frac{o}{T^{2}}-\frac{1}{2} h K e^{\alpha_{1} L-\lambda\left(1+d_{1} L\right) P} .
$$

To get the first-order conditions for profit maximization, setting $\frac{\partial T P_{1}(L, P, T)}{\partial P}=0$ and $\frac{\partial T P_{1}(L, P, T)}{\partial T}=0$, and simplifying terms, the critical point is obtained to maximize $T P_{1}(L, P, T)$ in (7) as follows:

$$
P_{1}(L)=\frac{\lambda\left(c+\frac{1}{2} h T\right)+1-\frac{1}{2} r L}{\lambda\left(1+d_{1} L\right)\left(1-\frac{1}{2} r L\right)}
$$

and

$$
T_{1}(L)=\sqrt{\frac{2 o}{h K e^{\alpha_{1} L-\lambda\left(1+d_{1} L\right) P}}}=\sqrt{\frac{2 o}{h D(L, P)}} .
$$

For any given $L \leq 0$, verifying the second-order conditions for a maximum $T P_{1}(L, P, T)$ in (7), we can demonstrate the optimal values of $P$ and $T$ for profit maximization as shown below.

Theorem 1 For any given $L \leq 0$, if $1-\frac{1}{2} r L \geq \frac{1}{4} \lambda h T_{1}(L)$, then the optimal values for $P$ and $T$ to maximize $T P_{1}(L, P, T)$ in $(7)$ are $P_{1}(L)$ as shown in (16), and $T_{1}(L)$ as given in (17), respectively.

Proof See "Appendix 1".

Generally speaking, the replenishment cycle $T_{1}(L)$ is less than a year. In addition, both $r$ and $\lambda$ are relatively small. As a result, we may assume in general that $1-\frac{1}{2} r L \geq \frac{1}{4} \lambda h T_{1}(L)$ if the product is not expensive (i.e., the holding cost per unit $h$ is small). By following (16) and (17), we may immediately obtain some analytical properties related to decision variables $P_{1}(L)$ and $T_{1}(L)$ as shown in the following Corollary.

Corollary 1 (1) The selling price $P_{1}(L)$ increases as the purchasing cost $c$, the coefficient of price discount $d_{1}$, the holding cost $h$, or the payment timing $L$ increases; while it decreases as the interest rate $r$ or the price coefficient of demand $\lambda$ increases.

(2) The replenishment cycle $T_{1}(L)$ climbs as the ordering cost c, or the selling price $P_{1}(L)$ increases; but it falls as the holding cost $h$, or the payment timing $L$ increases.

Proof

$$
P_{1}(L)=\frac{\lambda\left(c+\frac{1}{2} h T\right)+1-\frac{1}{2} r L}{\lambda\left(1+d_{1} L\right)\left(1-\frac{1}{2} r L\right)}=\frac{c+\frac{1}{2} h T}{\left(1+d_{1} L\right)\left(1-\frac{1}{2} r L\right)}+\frac{1}{\lambda\left(1+d_{1} L\right)} .
$$

Hence, $P_{1}(L)$ is decreasing in both $r$ and $\lambda$. This completes the proof. 
On the other hand, for any given $P \geq 0$ and $T \geq 0$, taking the first-order derivatives of $T P_{1}(L, P, T)$ in (7) with respect to $L$, and simplifying terms, we obtain

$$
\begin{aligned}
\frac{d T P_{1}(L, P, T)}{d L}= & K e^{\alpha_{1} L-\lambda\left(1+d_{1} L\right) P}\left\{\left(\alpha_{1}-\lambda d_{1} P\right)\left[\left(1-\frac{1}{2} r L\right)\left(1+d_{1} L\right) P-c-\frac{1}{2} h T\right]\right. \\
& \left.-\frac{1}{2}\left(1+d_{1} L\right) r P+\left(1-\frac{1}{2} r L\right) d_{1} P\right\} .
\end{aligned}
$$

For any given $P \geq 0$ and $T \geq 0$, setting $\frac{d T P_{1}(L, P, T)}{d L}=0$, and simplifying terms, we obtain the critical point to maximize $T P_{1}(L, P, T)$ in (7) as follows:

$$
\begin{aligned}
& \frac{1}{2}\left(\alpha_{1}-\lambda d_{1} P\right) d_{1} r P L^{2}+\left[\left(\alpha_{1}-\lambda d_{1} P\right)\left(\frac{1}{2} r-d_{1}\right)+d_{1} r\right] P L \\
& \quad-\left[\left(\alpha_{1}-\lambda d_{1} P\right)\left(P-c-\frac{1}{2} h T\right)+d_{1} P-\frac{1}{2} r P\right] \\
& \quad \equiv a_{1} L^{2}+a_{2} L+a_{3}=0,
\end{aligned}
$$

where

$$
\begin{gathered}
a_{1}=\frac{1}{2}\left(\alpha_{1}-\lambda d_{1} P\right) d_{1} r P \geq 0, \\
a_{2}=\left[\left(\alpha_{1}-\lambda d_{1} P\right)\left(\frac{1}{2} r-d_{1}\right)+d_{1} r\right] P,
\end{gathered}
$$

and

$$
a_{3}=-\left(\alpha_{1}-\lambda d_{1} P\right)\left(P-c-\frac{1}{2} h T\right)-d_{1} P+\frac{1}{2} r P<0 .
$$

Note that interest rate $r$ in general is significantly less than price discount rate $d_{1}$ in today's low inflation environment. Consequently, if $\alpha_{1}-\lambda d_{1} P=0$, then (20) is reduced to $d_{1} r P L-$ $\left(d_{1}-\frac{r}{2}\right) P=0$, which implies there is a unique positive solution $L_{1}(P, T)=\frac{1}{r}-\frac{d_{1}}{2}$. Likewise, we can prove that there exists a unique positive solution to (20), if $\alpha_{1}-\lambda d_{1} P>0$. Therefore, we conclude in Theorem 2 below that there exists a unique positive solution $L_{1}(P, T)$ which maximizes $T P_{1}(L, P, T)$ in (7) for any given $P \geq 0$ and $T \geq 0$.

Theorem 2 For any given $P \geq 0$ and $T \geq 0$, if $\left(\alpha_{1}-\lambda d_{1} P\right)\left[(1-r L) d_{1}-\frac{1}{2} r\right]-d_{1} r \leq 0$, then the optimal solution for $L$ to maximize $T P_{1}(L, P, T)$ in $(7)$ is the unique positive solution to $(20)$.

Proof See "Appendix 2".

Next, we discuss the case of credit payment.

\subsection{The optimal solution to $\Pi_{2}$}

Similarly, for any chosen $L \geq 0$, taking the first-order partial derivatives of $T P_{2}(L, T, P)$ in (11) with respect to $P$ and $T$, and re-arranging terms, we have

$$
\frac{\partial T P_{2}(L, P, T)}{\partial P}=K e^{\alpha_{2} L-\lambda P}\left[(1-\lambda P)\left(e^{-d_{2} L}-\frac{1}{2} r L\right)+\lambda\left(c+\frac{1}{2} h T\right)\right],
$$

and

$$
\frac{\partial T P_{2}(L, P, T)}{\partial T}=\frac{o}{T^{2}}-\frac{1}{2} h K e^{\alpha_{2} L-\lambda P} .
$$


Likewise, to obtain the first-order conditions for profit maximization, by setting $\frac{\partial T P_{2}(L, P, T)}{\partial P}=0$ and $\frac{\partial T P_{2}(L, P, T)}{\partial T}=0$, and re-arranging terms, the critical point is obtained to maximize $T P_{2}(L, T, P)$ in (11) as follows:

$$
P_{2}(L)=\frac{1}{\lambda}+\frac{c+\frac{1}{2} h T}{e^{-d_{2} L}-\frac{1}{2} r L},
$$

and

$$
T_{2}(L)=\sqrt{\frac{2 o}{h K e^{\alpha_{2} L-\lambda P}}}=\sqrt{\frac{2 o}{h D(L, P)}} .
$$

For any chosen $L \geq 0$, verifying the second-order conditions for a maximum $T P_{2}(L, T, P)$ in (11), we can prove that the optimal values of $P$ and $T$ for profit maximization are given below.

Theorem 3 For any chosen $L \geq 0$, if $\left[\left(e^{-d_{2} L}-\frac{1}{2} r L\right) \frac{1}{T}-\frac{\lambda h}{4}\right] \geq 0$, then the optimal values for $P$ and $T$ to maximize $T P_{2}(L, T, P)$ in (11) are $P_{2}(L)$ as shown in (26), and $T_{2}(L)$ as given in (27), respectively.

Proof See "Appendix 3".

Similar to Corollary 1, following from (26) and (27), we immediately get some analytical properties for the decision variables $P_{2}(L)$ and $T_{2}(L)$ as given in Corollary 2 below.

Corollary 2 (1) The selling price $P_{2}(L)$ increases as the purchasing cost $c$, the coefficient of default risk $d_{2}$, the holding cost $h$, the payment timing $L$, or the interest rate $r$ increases; while it decreases as the price coefficient of demand $\lambda$ increases.

(2) The replenishment cycle $T_{2}(L)$ elevates as the ordering cost c, or the selling price $P_{1}(L)$ climbs; but it falls as the holding cost $h$, or the payment timing $L$ increases.

Proof It immediately follows from (26) and (27).

For any given $P \geq 0$ and $T \geq 0$, taking the first-order derivatives of $T P_{2}(L, T, P)$ in (11) with respect to $L$, and simplifying terms, we derive

$$
\frac{d T P_{2}(L, P, T)}{d L}=K e^{\alpha_{2} L-\lambda P}\left[P\left(\alpha_{2}-d_{2}\right) e^{-d_{2} L}-\frac{1}{2} r P\left(1+\alpha_{2} L\right)-\frac{1}{2} \alpha_{2} h T-\alpha_{2} c\right] .
$$

By setting $\frac{d T P_{2}(L, P, T)}{d L}=0$, and re-arranging terms, the critical point is obtained to maximize $T P_{2}(L, P, T)$ in (11) as follows:

$$
P\left(\alpha_{2}-d_{2}\right) e^{-d_{2} L}-\frac{1}{2} \alpha_{2} r L P-\left(\frac{1}{2} r P+\frac{1}{2} \alpha_{2} h T+\alpha_{2} c\right)=0 .
$$

Theorem 4 For any given $P \geq 0$ and $T \geq 0$, if $P\left(\alpha_{2}-d_{2}\right) \geq \frac{1}{2} r P+\frac{1}{2} \alpha_{2} h T+\alpha_{2} c$, then the optimal solution for $L$ to maximize $T P_{2}(L, P, T)$ in (11) is the unique positive solution to (29).

Proof See "Appendix 4". 
Table 2 Impacts of $a_{1}$ and $a_{2}$ on the seller's decisions

\begin{tabular}{lllllllll}
\hline$a_{1}$ or $a_{2}$ & \multicolumn{1}{c}{$L_{1}^{*}$} & $P_{1}^{*}$ & $T_{1}^{*}$ & $T P_{1}^{*}$ & $L_{2}^{*}$ & $P_{2}^{*}$ & $T_{2}^{*}$ & $T P_{2}^{*}$ \\
\hline 0.0053 & -0.763 & 33.21 & 0.76 & 1259.22 & 0.000 & 30.68 & 0.68 & 1249.91 \\
0.0153 & -0.198 & 31.28 & 0.68 & 1249.92 & 0.000 & 30.68 & 0.68 & 1249.91 \\
0.1153 & 0.000 & 30.68 & 0.68 & 1249.91 & 0.000 & 30.68 & 0.68 & 1249.91 \\
0.2153 & 0.000 & 30.68 & 0.68 & 1249.91 & 0.578 & 31.52 & 0.65 & 1253.04 \\
0.3153 & 0.000 & 30.68 & 0.68 & 1249.91 & 2.028 & 35.91 & 2.03 & 1412.09
\end{tabular}

\section{Numerical examples and managerial insights}

In this coronavirus pandemic, online business transactions have grown exponentially since each party does not need to be physically present in order to make the transaction. To encourage customers to "buy now and pay later", a store owner for commodity items may grant customers a credit payment (e.g., accepting credit cards). However, these credit payments can present additional risks of fraud and disputed or revoked payments for businesses. To avoid unnecessary risks, a seller for perishable or deteriorating items would prefer an advance payment such as store's gift cards which are prepaid stored-value money cards. Furthermore, the seller for special event tickets or luxury goods could have a strong preference for authenticated or irrevocable cash payments such as debit cards or automated clearing house (ACH) disbursements. Consequently, there are three basic ways for a seller to accept payments online - advance, cash, and credit.

In order to illustrate the results and to highlight the impacts of the financial related parameters to optimal solutions, the following parametric values are used: $c=10, d_{1}=0.1, d_{2}=$ $0.125, K=300, h=2, o=30, r=0.02$, and $\lambda=0.1$.

First of all, the impacts of $\alpha_{1}$ and $\alpha_{2}$ on the seller's decisions are given in Table 2. For example, if $\alpha_{1}=0.0153$, then $L_{1}^{*}=-0.198, P_{1}^{*}=31.28, T_{1}^{*}=0.682$, and $T P_{1}^{*}=$ $T P_{1}\left(L_{1}^{*}, P_{1}^{*}, T_{1}^{*}\right)=1249.92$. For given $L_{1}^{*}=-0.198$, the graphical representation of $T P_{1}\left(L_{1}^{*}=-0.198, P_{1}, T_{1}\right)$ is given in Fig. 1 , which is indeed a concave function in $P_{1}$ and $T_{1}$ as demonstrated in Theorem 1. Note that the black point in Fig. 1 is the location of the optimal solution. Likewise, for given $P_{1}^{*}=31.28$, and $T_{1}^{*}=0.682$, the graphical representation of $T P_{1}\left(L_{1}, P_{1}^{*}=31.28, T_{1}^{*}=0.682\right)$ is depicted in Fig. 2 as a strictly concave function in $L_{1}$, which is consistent with the result in Theorem 2.

On the other hand, if $\alpha_{2}=0.2153$, then $L_{2}^{*}=0.578, P_{2}^{*}=31.52, T_{2}^{*}=0.650$, and $T P_{2}^{*}=T P_{2}\left(L_{2}^{*}, P_{2}^{*}, T_{2}^{*}\right)=1253.04$. For given $L_{2}^{*}=0.578$, the graphical representation of $T P_{2}\left(L_{2}^{*}=0.578, P_{2}, T_{2}\right)$ is presented in Fig. 3, which is a concave function in $P_{2}$ and $T_{2}$ as proven in Theorem 3. Again, the black point in Fig. 3 is the location of the optimal solution. Additionally, for given $P_{2}^{*}=31.52$, and $T_{2}^{*}=0.650$, the graphical representation of $T P_{2}\left(L_{2}, P_{2}^{*}=31.52, T_{2}^{*}=0.65\right)$ is shown in Fig. 4 clearly as a strictly concave function in $L_{2}$, which is demonstrated in Theorem 4.

Consequently, if $\alpha_{1}=0.0153$ and $\alpha_{2}=0.2153$, then the seller's optimal decision is to offer a credit payment to buyers with a selling price of $\$ 31.52$, a downstream credit period of 0.578 years, and a total profit per unit of $\$ 1253.04$.

Numerical examples in Table 2 reveal the following important managerial insights:

1. If $\alpha_{1}=\alpha_{2} \leq 0.0153$, then an advance payment provides the highest profit per unit time for the seller;

2. If $\alpha_{1}=\alpha_{2}=0.1153$, then the seller's best decision is a cash payment; and 


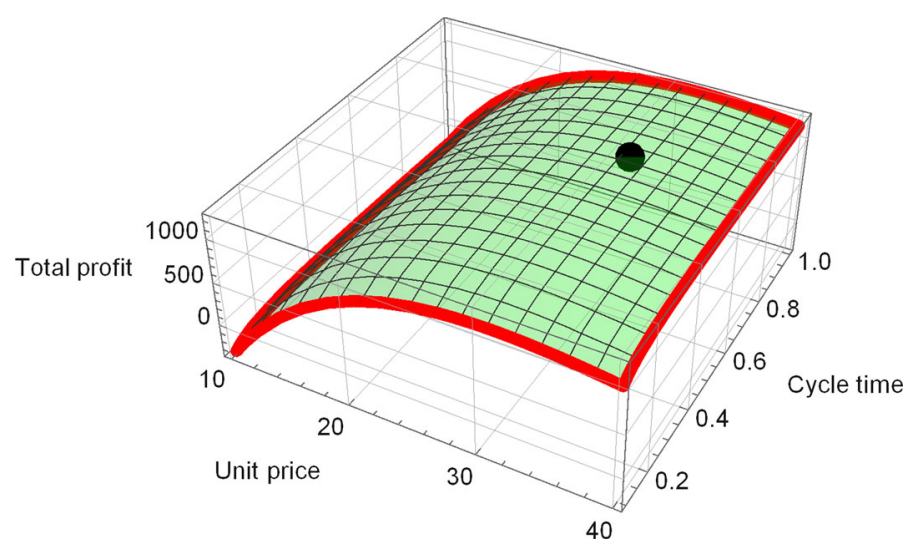

Fig. 1 Graphical representation of $T P_{1}\left(L_{1}^{*}=-0.198, P_{1}, T_{1}\right)$

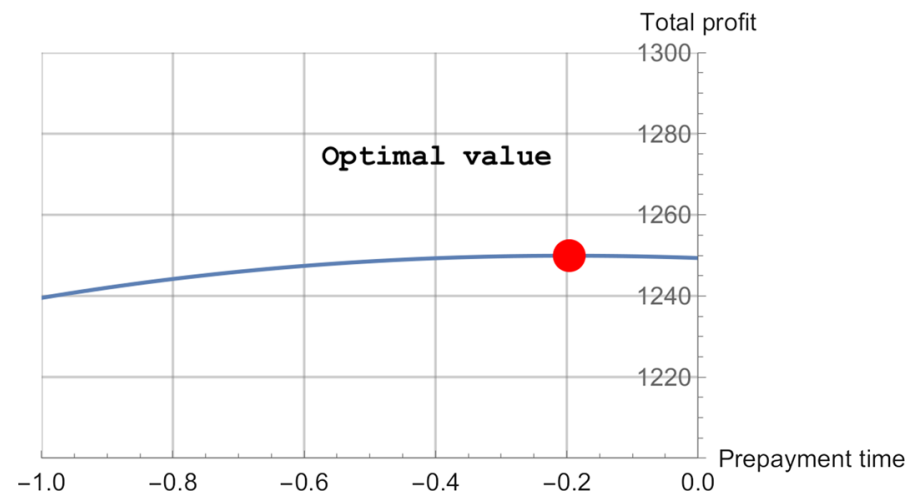

Fig. 2 Graphical representation of $T P_{1}\left(L_{1}, P_{1}^{*}=31.28, T_{1}^{*}=0.682\right)$

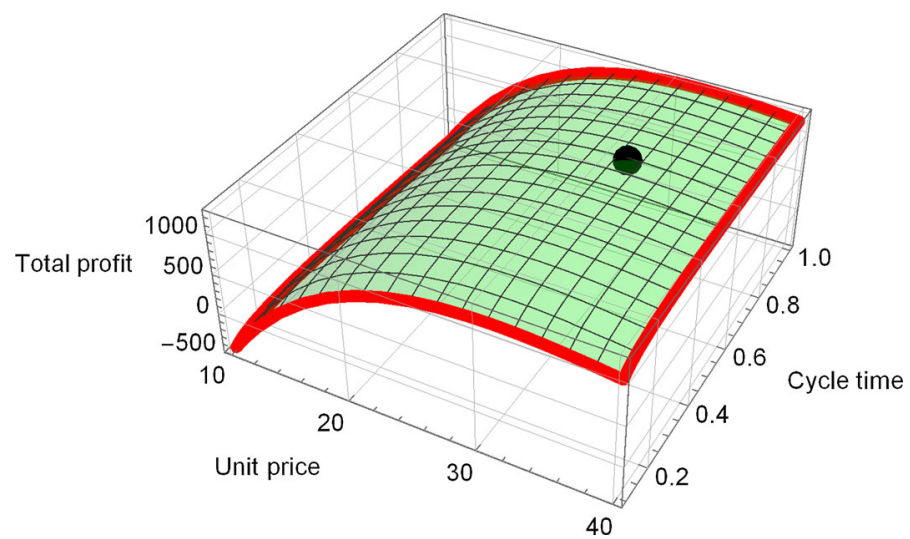

Fig. 3 Graphical representation of $T P_{2}\left(L_{2}^{*}=0.578, P_{2}, T_{2}\right)$

3. If $\alpha_{1}=\alpha_{2} \geq 0.2153$, then the credit payment provides the seller the best profit per unit time among three payments options. 


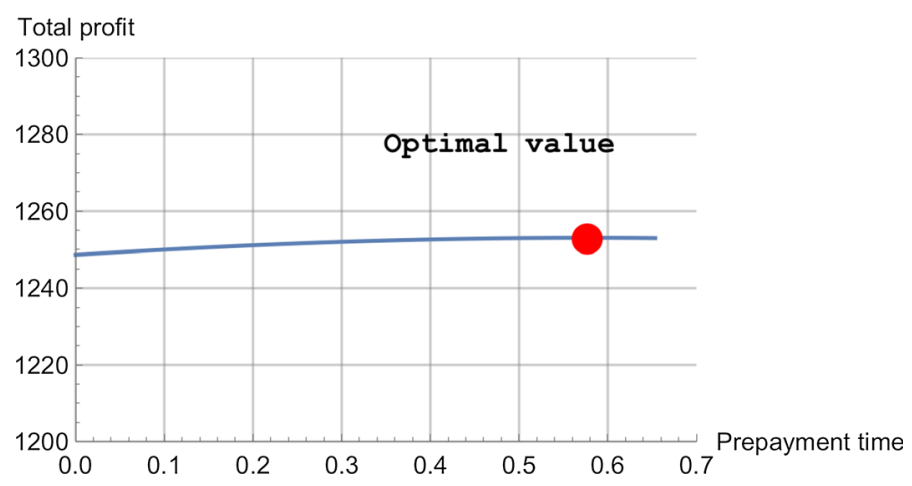

Fig. 4 Graphical representation of $T P_{2}\left(L_{2}, P_{2}^{*}=31.52, T_{2}^{*}=0.65\right)$

Table 3 The impacts of price discount on the seller's decisions

\begin{tabular}{lrrllllll}
\hline$d_{1}$ & \multicolumn{1}{l}{$L_{1}^{*}$} & \multicolumn{1}{c}{$P_{1}^{*}$} & $T_{1}^{*}$ & \multicolumn{1}{c}{$T P_{1}^{*}$} & $L_{2}^{*}$ & $P_{2}^{*}$ & $T_{2}^{*}$ & $T P_{2}^{*}$ \\
\hline 0.00 & 0.00 & 100.00 & 3.85 & 166.35 & 0.58 & 31.52 & 0.65 & 1253.04 \\
0.10 & -0.20 & 31.28 & 0.68 & 1249.92 & 0.58 & 31.52 & 0.65 & 1253.04 \\
0.15 & -0.20 & 31.60 & 0.68 & 1249.92 & 0.58 & 31.52 & 0.65 & 1253.04 \\
0.20 & -0.20 & 31.92 & 0.68 & 1249.92 & 0.58 & 31.52 & 0.65 & 1253.04 \\
0.25 & -0.20 & 32.26 & 0.68 & 1249.92 & 0.58 & 31.52 & 0.65 & 1253.04
\end{tabular}

In summary, a high value of $\alpha_{2}$, that is, a high demand rate with a credit payment, not only elevates the selling price but also leads to a credit payment. On the other hand, a low value of $\alpha_{1}$, which is a small demand loss with an advance payment, also elevates the selling price but the best decision is to offer an advance payment.

Second, the impacts of price discount $d_{1}$ for an advance payment are investigated on the seller's decisions as shown in Table 3. From Table 3, the following noteworthily managerial insights are obtained:

1. Offering a price discount is essentially necessary for advance payments by comparing the profit of $\$ 166.35$ with $d_{1}=0$ and the profit of $\$ 1249.92$ with $d_{1}=0.1$; and

2. An increase in price discount rate $d_{1}$ causes a small increase in selling price.

Thirdly, the impacts of default risk $d_{2}$ for a credit payment are explored on the seller's decisions as obtained in Table 4 . The following essentially managerial insights are observed from Table 4 as follows:

1. An increase in default risk reduces selling price, cycle time, payment period, and total profit simultaneously.

2. The credit payment is the best payment optimal for the seller when the default risk is relatively small.

Finally, the impacts of price coefficient of demand $\lambda$ on the seller's decisions are observed as obtained in Table 5. Table 5 reveals the following managerial results:

1. An advance payment yields more profit for the seller than a credit payment if $\lambda$ is relatively higher (i.e. the demand is more sensitive to price increase), and vice versa; 
Table 4 The impact of default risk on the seller's decisions

\begin{tabular}{lllllllll}
\hline$d_{2}$ & $L_{1}^{*}$ & $P_{1}^{*}$ & $T_{1}^{*}$ & $T P_{1}^{*}$ & $L_{2}^{*}$ & $P_{2}^{*}$ & $T_{2}^{*}$ & $T P_{2}^{*}$ \\
\hline 0.075 & -0.198 & 31.28 & 0.682 & 1249.92 & 2.376 & 35.22 & 2.376 & 1385.58 \\
0.100 & -0.198 & 31.28 & 0.682 & 1249.92 & 1.011 & 32.32 & 1.011 & 1294.87 \\
0.125 & -0.198 & 31.28 & 0.682 & 1249.92 & 0.578 & 31.52 & 0.653 & 1253.04 \\
0.150 & -0.198 & 31.28 & 0.682 & 1249.92 & 0.000 & 30.68 & 0.681 & 1249.91 \\
\hline
\end{tabular}

Table 5 The impact of $\lambda$ on the seller's decisions

\begin{tabular}{llllllllr}
\hline$\lambda$ & \multicolumn{1}{l}{$L_{1}^{*}$} & $P_{1}^{*}$ & $T_{1}^{*}$ & $T P_{1}^{*}$ & $L_{2}^{*}$ & $P_{2}^{*}$ & $T_{2}^{*}$ & $T P_{2}^{*}$ \\
\hline 0.025 & 0.000 & 50.59 & 0.595 & 3336.87 & 1.481 & 54.07 & 1.481 & 3466.58 \\
0.050 & -0.198 & 31.28 & 0.682 & 1249.92 & 0.578 & 31.52 & 0.653 & 1253.04 \\
0.075 & -0.798 & 26.13 & 0.798 & 618.53 & 0.000 & 24.11 & 0.781 & 617.14 \\
0.100 & -0.927 & 22.96 & 0.927 & 339.58 & 0.000 & 20.89 & 0.899 & 337.73 \\
\hline
\end{tabular}

2. For credit payment, a higher value of $\lambda$ drastically reduces selling price, payment period, and total profit; and

3. For advance payment, an increase in $\lambda$ tremendously increases both payment period and cycle time, while enormously reducing selling price and total profit.

\section{Conclusions}

Although research on pricing and lot-sizing decisions with respect to a single payment type or a combination of two payment types has been extensive, almost all of it has been done from the buyer's perspective. In this paper, to the best of our knowledge, we have first established a joint operation, marketing, and finance model from the seller's perspective. We have developed the seller's profit under each of the three payment terms: advance, cash and credit.

Moreover, we have obtained explicitly optimal solutions to the problem, and thus theoretically demonstrated the relationship between each parameter and the optimal solution. To obtain managerial insights, we have performed sensitivity analyses to examine the influences of financially related parameters on the seller's decisions and profits. For example, an advance payment generates more profit than a credit payment if the sales volume from a credit payment to an advance payment declines insignificantly. Conversely, if the sales volume from a credit payment to an advance payment falls significantly, then a credit payment creates more profit than an advance payment. Likewise, it is critically important to offer a price discount when the seller asks buyers for an advance payment.

This model can be extended in many directions. As consumers become more healthconscious, the demand for perishable goods, especially organic foods, has increased dramatically in recent years. Additionally, a large pile of seasonal goods such as apples, corns, peaches, etc. in a supermarket often induces consumers to buy more. Hence, the demand could be expanded as a function of selling price, displayed stocks, and time varying as stipulated in Jaggi et al. (2019), Mishra et al. (2017) and Tiwari et al. (2017). Furthermore, in today's supply chain coordination, we may explore the model from a single player's - the 
seller's-optimal solution to a two-player-the sellers and the buyers-win-win cooperative Pareto, or integrated solution. Finally, for generality, we could investigate the model by allowing for shortages, partial backordering, and others.

Acknowledgements The authors sincerely appreciate Editor-in-Chief Endre Boros and two anonymous reviewers for their encouragement and constructive suggestions. The authors also would like to acknowledge the valuable comments by Professor Biswajit Sarkar on an earlier version of this paper. The principal author's research was supported by the National Nature Science Foundation of China Nos. 71601162 and 71671146. The corresponding author's research was funded by the Assigned Released Time for Research from William Paterson University of New Jersey and a research grant from Chaoyang University of Technology in ROC.

\section{Appendix 1: Proof of Theorem 1}

For any chosen $L \leq 0$, taking the second-order conditions for a maximum $T P_{1}(L, P, T)$ in (7) at the critical point, we derive the results as follows:

$$
\begin{gathered}
\left.\frac{\partial^{2} T P_{1}(L, P, T)}{\partial P^{2}}\right|_{P=P_{1}(L)}=-\left.\lambda\left(1+d_{1} L\right)^{2}\left(1-\frac{1}{2} r L\right) K e^{\alpha_{1} L-\lambda\left(1+d_{1} L\right) P}\right|_{P=P_{1}(L)}<0, \\
\frac{\partial^{2} T P_{1}(L, P, T)}{\partial T^{2}}=-\frac{2 o}{T^{3}}<0
\end{gathered}
$$

and

$$
\frac{\partial^{2} T P_{1}(L, P, T)}{\partial P \partial T}=\frac{1}{2} h \lambda\left(1+d_{1} L\right) K e^{\alpha_{1} L-\lambda\left(1+d_{1} L\right) P}>0 .
$$

For any given $L \leq 0$, to prove the associated Hessian Matrix is strictly negative definite at the critical point, we derive

$$
\begin{gathered}
{\left.\left[\frac{\partial^{2} T P_{1}(L, P, T)}{\partial P^{2}} \frac{\partial^{2} T P_{1}(L, P, T)}{\partial T^{2}}-\left(\frac{\partial^{2} T P_{1}(L, P, T)}{\partial P \partial T}\right)\right]\right|_{P=P_{1}(L)}=} \\
\lambda\left(1+d_{1} L\right)^{2}\left(1-\frac{1}{2} r L\right) K e^{\alpha_{1} L-\lambda\left(1+d_{1} L\right) P}\left(\frac{2 o}{T^{3}}\right)-\left[\frac{1}{2} h \lambda\left(1+d_{1} L\right) K e^{\alpha_{1} L-\lambda\left(1+d_{1} L\right) P}\right]^{2} .
\end{gathered}
$$

By using (17), and re-arranging terms, we yield

$$
\begin{array}{r}
{\left.\left[\frac{\partial^{2} T P_{1}(L, P, T)}{\partial P^{2}} \frac{\partial^{2} T P_{1}(L, P, T)}{\partial T^{2}}-\left(\frac{\partial^{2} T P_{1}(L, P, T)}{\partial P \partial T}\right)\right]\right|_{P=P_{1}(L), T=T_{1}(L)}=} \\
\lambda h\left(1+d_{1} L\right)^{2}\left[K e^{\alpha_{1} L-\lambda\left(1+d_{1} L\right) P}\right]^{2}\left[\left(1-\frac{1}{2} r L\right) \frac{1}{T}-\frac{h \lambda}{4}\right] \geq 0,
\end{array}
$$

if $\left(1-\frac{1}{2} r L\right) \geq \frac{1}{4} \lambda h T$. This completes the proof. 


\section{Appendix 2: Proof of Theorem 2}

For any given $P \geq 0$ and $T \geq 0$, taking the second-order condition for a maximum $T P_{1}(L, P, T)$ in (7) at the critical point, we derive the result as follows:

$$
\begin{aligned}
& \left.\frac{d^{2} T P_{1}(L, P, T)}{d L^{2}}\right|_{L=L_{1}(P, T)} \\
& =K e^{\alpha_{1} L-\lambda\left(1+d_{1} L\right) P} P\left\{\left(\alpha_{1}-\lambda d_{1} P\right)\left[(1-r L) d_{1}-\frac{1}{2} r\right]-d_{1} r\right\} \leq 0 .
\end{aligned}
$$

In addition, if $\alpha_{1}-\lambda d_{1} P>0$, then $a_{1}>0$ and $a_{3}<0$. As a result, we can conclude that there exists a unique positive solution $L_{1}(P, T)$ to (20) such that $T P_{1}(L, P, T)$ in (7) is maximized in a real-world problem. This completes the proof.

\section{Appendix 3: Proof of Theorem 3}

For any chosen $L \geq 0$, taking the second-order conditions for a maximum $T P_{2}(L, T, P)$ in (11) at the critical point, we derive the results as follows:

$$
\begin{gathered}
\left.\frac{\partial^{2} T P_{2}(L, P, T)}{\partial P^{2}}\right|_{P=P_{2}(L)}=-\lambda K e^{\alpha_{2} L-\lambda P}\left(e^{-d_{2} L}-\frac{1}{2} r L\right) \leq 0, \\
\frac{\partial^{2} T P_{2}(L, P, T)}{\partial T^{2}}=-\frac{2 o}{T^{3}}<0,
\end{gathered}
$$

and

$$
\frac{\partial^{2} T P_{2}(L, P, T)}{\partial P \partial T}=\frac{1}{2} \lambda h K e^{\alpha_{2} L-\lambda P}>0 .
$$

Again, to verify the associated Hessian Matrix is strictly negative definite at the critical point, we get

$$
\begin{aligned}
& {\left.\left[\frac{\partial^{2} T P_{2}}{\partial P^{2}} \frac{\partial^{2} T P_{2}}{\partial T^{2}}-\left(\frac{\partial^{2} T P_{2}}{\partial T \partial P}\right)^{2}\right]\right|_{P=P_{2}(L)}=\lambda K e^{\alpha_{2} L-\lambda P}\left(e^{-d_{2} L}-\frac{1}{2} r L\right)\left(\frac{2 o}{T^{3}}\right)} \\
& -\left(\frac{1}{2} \lambda h K e^{\alpha_{2} L-\lambda P}\right)^{2}
\end{aligned}
$$

By applying (27), and re-arranging terms, we yield

$$
\begin{aligned}
& {\left.\left[\frac{\partial^{2} T P_{2}}{\partial P^{2}} \frac{\partial^{2} T P_{2}}{\partial T^{2}}-\left(\frac{\partial^{2} T P_{2}}{\partial T \partial P}\right)^{2}\right]\right|_{P=P_{2}(L), T=T_{2}(L)}} \\
& =\left(K e^{\alpha_{2} L-\lambda P}\right)^{2} \lambda h\left[\left(e^{-d_{2} L}-\frac{1}{2} r L\right) \frac{1}{T}-\frac{\lambda h}{4}\right] \geq 0,
\end{aligned}
$$

if $\left[\left(e^{-d_{2} L}-\frac{1}{2} r L\right) \frac{1}{T}-\frac{\lambda h}{4}\right] \geq 0$. This completes the proof. 


\section{Appendix 4: Proof of Theorem 4}

For any given $P \geq 0$ and $T \geq 0$, taking the second-order condition for a maximum $T P_{2}(L, P, T)$ in (11) at the critical point, we get the following result.

$$
\left.\frac{d^{2} T P_{2}(L, P, T)}{d L^{2}}\right|_{L=L_{1}(P, T)}=-K e^{\alpha_{2} L-\lambda P} P\left[d_{2}\left(\alpha_{2}-d_{2}\right) e^{-d_{2} L}+\frac{1}{2} \alpha_{2} r\right]<0 .
$$

To prove that there exists a unique solution to (29), let us set

$$
F(L)=P\left(\alpha_{2}-d_{2}\right) e^{-d_{2} L}-\frac{1}{2} \alpha_{2} r L P-\left(\frac{1}{2} r P+\frac{1}{2} \alpha_{2} h T+\alpha_{2} c\right) .
$$

It is clear that $F(L)$ is continuous in $L, F(0)=P\left(\alpha_{2}-d_{2}\right)-\left(\frac{1}{2} r P+\frac{1}{2} \alpha_{2} h T+\alpha_{2} c\right)>0$, and $F(\infty)=-\infty$. Applying the Mean Value Theorem and (D1), we know that there exists a unique positive solution $L_{2}(P, T)$ to (29) such that $T P_{2}(L, P, T)$ in (11) is maximized. This completes the proof.

\section{References}

Chang, C.-T., Cheng, M.-C., \& Ouyang, L.-Y. (2015). Optimal pricing and ordering policies for noninstantaneously deteriorating items under order-size-dependent delay in payments. Applied Mathematical Modelling, 39(2), 747-763.

Chang, C.-T., Ouyang, L.-Y., Teng, J.-T., Lai, K. K., \& Cárdenas-Barrón, L. E. (2019). Manufacturer's pricing and lot-sizing decisions for perishable goods under various payment terms by a discounted cash flow analysis. International Journal of Production Economics, 218(12), 83-95.

Chang, C.-T., Teng, J.-T., \& Chern, M.-S. (2010). Optimal manufacturer's replenishment policies for deteriorating items in a supply chain with up-stream and down-stream trade credits. International Journal of Production Economics, 127(1), 197-202.

Chang, C.-T., Teng, J.-T., \& Goyal, S. K. (2008). Inventory lot-size models under trade credits: A review. Asia-Pacific Journal Operational Research, 25(1), 89-112.

Chang, H.-C., Ho, C.-H., Ouyang, L.-Y., \& Su, C.-H. (2009). The optimal pricing and ordering policy for an integrated inventory model when trade credit linked to order quantity. Applied Mathematical Modelling, 33(7), 2978-2991.

Chen, S.-C., \& Teng, J.-T. (2015). Inventory and credit decisions for time-varying deteriorating items with up-stream and down-stream trade credit financing by discounted cash-flow analysis. European Journal of Operational Research, 243(2), 566-575.

Chern, M.-S., Chan, Y.-L., Teng, J.-T., \& Goyal, S. K. (2014). Nash equilibrium solution in a vendor-buyer supply chain model with permissible delay in payments. Computers and Industrial Engineering, 70(21), 116-123.

Chern, M.-S., Pan, Q., Teng, J.-T., Chan, Y.-L., \& Chen, S.-C. (2013). Stackelberg solution in a vendor-buyer supply chain model with permissible delay in payments. International Journal of Production Economics, 144(1), 397-404.

Feng, L., \& Chan, Y.-L. (2019). Joint pricing and production decisions for new products with learning curve effects under upstream and downstream trade credits. European Journal of Operational Research, 272(3), 905-913.

Feng, L., Chan, Y.-L., \& Cárdenas-Barrón, L. E. (2017). Pricing and lot-sizing policies for perishable goods when the demand depends on selling price, displayed stocks, and expiration date. International Journal of Production Economics, 185(C), 11-20.

Ho, C.-H., Ouyang, L.-Y., \& Su, C.-H. (2008). Optimal pricing, shipment and payment policy for an integrated supplier-buyer inventory model with two-part trade credit. European Journal of Operational Research, 187(2), 496-510.

Hwang, H., \& Shinn, S. W. (1997). Retailer's pricing and lot sizing policy for exponentially deteriorating products under the condition of permissible delay in payments. Computers and Operations Research, 24(6), 539-547. 
Jaggi, C. K., Goyal, S. K., \& Goel, S. K. (2008). Retailer's optimal replenishment decisions with creditlinked demand under permissible delay in payments. European Journal of Operational Research, 190(1), $130-135$.

Jaggi, C. K., Gupta, M., Kausar, A., \& Tiwari, S. (2019). Inventory and credit decisions for deteriorating items with displayed stock dependent demand in two-echelon supply chain using Stackelberg and Nash equilibrium solution. Annals of Operations Research, 274(1-2), 309-329.

Jaggi, C. K., Pareek, S., Khanna, A., \& Sharma, R. (2014). Credit financing in a two-warehouse environment for deteriorating items with price-sensitive demand and fully backlogged shortages. Applied Mathematical Modelling, 38(21-22), 5315-5333.

Lashgari, M., Taleizadeh, A. A., \& Ahmadi, A. (2016). Partial up-stream advanced payment and partial downstream delayed payment in a three-level supply chain. Annals of Operations Research, 238, 329-354.

Li, R., Chan, Y.-L., Chang, C.-T., \& Cárdenas-Barrón, L. E. (2017). Pricing and lot-sizing policies for perishable products with advance-cash-credit payments by a discounted cash-flow analysis. International Journal of Production Economics, 193(C), 578-589.

Li, R., Liu, Y., Teng, J.-T., \& Tsao, Y.-C. (2019a). Optimal pricing, lot-sizing and backordering decisions when a seller demands for an advance-cash-credit payment scheme. European Journal of Operational Research, 278(1), 283-295.

Li, R., Skouri, K., Teng, J.-T., \& Yang, W.-G. (2018). Seller's optimal replenishment policy and payment term among advance, cash, and credit payments. International Journal of Production Economics, 197(8), $35-42$.

Li, R., \& Teng, J.-T. (2018). Pricing and lot-sizing decisions for perishable goods when demand depends on selling price, reference price, product freshness, and displayed stocks. European Journal of Operational Research, 270(3), 1099-1108.

Li, R., Teng, J.-T., \& Zheng, Y. (2019b). Optimal credit term, order quantity and pricing policies for perishable products when demand depends on price, expiration date, and credit period. Annals of Operations Research, 280(1-2), 377-405.

Mahata, G. C. (2015). Partial trade credit policy of retailer in economic order quantity models for deteriorating items with expiration dates and price sensitive demand. Journal of Mathematical Modelling and Algorithms in Operations Research, 14, 363-392.

Maiti, A. K., Maiti, M. K., \& Maiti, M. (2009). Inventory model with stochastic lead-time and price dependent demand incorporating advance payment. Applied Mathematical Modelling, 33(5), 2433-2443.

Mishra, U., Cárdenas-Barrón, L. E., Tiwari, S., Shaikh, A. A., \& Treviño-Garza, G. (2017). An inventory model under price and stock dependent demand for controllable deterioration rate with shortages and preservation technology investment. Annals of Operations Research, 254(1-2), 165-190.

Mishra, U., Tijerina-Aguilera, J., Tiwari, S., \& Cárdenas-Barrón, L. E. (2018). Retailer's joint ordering, pricing, and preservation technology investment policies for a deteriorating item under permissible delay in payments. Mathematical Problems in Engineering, 2018, 6962417. https://doi.org/10.1155/2018/696 2417.

Ouyang, L.-Y., Ho, C.-H., \& Su, C.-H. (2009). An optimization approach for joint pricing and ordering problem in an integrated inventory system with order-size dependent trade credit. Computer and Industrial Engineering, 57(3), 920-930.

Robinson, B., \& Lakhani, C. (1975). Dynamic price models for new-product planning. Management Science, 21(6), 1113-1122.

Seifert, D., Seifert, R. W., \& Protopappa-Sieke, M. (2013). A review of trade credit literature: opportunity for research in operations. European Journal of Operational Research, 231(2), 245-256.

Taleizadeh, A. A. (2014). An EOQ model with partial backordering and advance payments for an evaporating item. International Journal of Production Economics, 155, 185-193.

Taleizadeh, A. A., Tavakoli, S., \& San-José, L. A. (2018). A lot sizing model with advance payment and planned backordering. Annals of Operations Research, 271, 1001-1022.

Taleizadeh, A. A., Tavassoli, S., \& Bhattacharya, A. (2020). An optimal ordering and replenishment policy for a vendor-buyer system under varying replenishment intervals and delayed payment. Annals of Operations Research, 287, 403-437.

Taleizadeh, A. A., Zarei, H. R., \& Sarker, B. R. (2019). An optimal ordering and replenishment policy for a vendor-buyer system under varying replenishment intervals and delayed payment. European Journal of Industrial Engineering, 13(2), 264-298.

Tavakoli, S., \& Taleizadeh, A. A. (2017). An EOQ model for decaying item with full advanced payment and conditional discount. Annals of Operations Research, 259, 417-436.

Teng, J.-T., Cárdenas-Barrón, L. E., Chang, H.-J., Wu, J., \& Hu, Y. (2016). Inventory lot-size policies for deteriorating items with expiration dates and advance payments. Applied Mathematical Modelling, 40(1-2), 8605-8616. 
Teng, J.-T., Chang, C.-T., \& Goyal, S. K. (2005). Optimal pricing and ordering policy under permissible delay in payments. International Journal of Production Economics, 97(2), 121-129.

Teng, J.-T., \& Lou, K.-R. (2012). Seller's optimal credit period and replenishment time in a supply chain with up-stream and down-stream trade credits. Journal of Global Optimization, 53(3), 417-430.

Teng, J.-T., Ouyang, L.-Y., \& Chen, L.-H. (2006). Optimal manufacturer's pricing and lot-sizing policies under trade credit financing. International Transactions in Operational Research, 13(6), 515-528.

Thangam, A. (2012). Optimal price discounting and lot-sizing policies for perishable items in a supply chain under advance payment scheme and two-echelon trade credits. International Journal of Production Economics, 139(2), 459-472.

Thangam, A., \& Uthayakumar, R. (2010). Optimal pricing and lot-sizing policy for a two-warehouse supply chain system with perishable items under partial trade credit financing. International Journal of Operational Research, 10(2), 133-161.

Thompson, G. L., \& Teng, J.-T. (1984). Optimal pricing and advertising policies for new product oligopoly models. Marketing Science, 3(2), 148-168.

Tiwari, S., Cardenas-Barron, L. E., Goh, M., \& Shaikh, A. A. (2018). Joint pricing and inventory model for deteriorating items with expiration dates and partial backlogging under two-level partial trade credits in supply chain. International Journal of Production Economics, 200(C), 16-36.

Tiwari, S., Jaggi, C. K., Bhunia, A. K., Shaikh, A. A., \& Goh, M. (2017). Two-warehouse inventory model for non-instantaneous deteriorating items with stock-dependent demand and inflation using particle swarm optimization. Annals of Operations Research, 254(1-2), 401-423.

Tsao, Y.-C., Zhang, Q., Fang, H.-P., \& Lee, P.-L. (2017). Two-tiered pricing and ordering for non-instantaneous deteriorating items under trade credit. International Journal of Operational Research. https://doi.org/1 $0.1007 / \mathrm{s} 12351-017-0306-9$.

Wang, W.-C., Teng, J.-T., \& Lou, K.-R. (2014). Seller's optimal credit period and cycle time in a supply chain for deteriorating items with maximum lifetime. European Journal of Operational Research, 232(2), $315-321$.

Wu, J., Teng, J.-T., \& Chan, Y.-L. (2018a). Inventory policies for perishable products with expiration dates and advance-cash-credit payment schemes. International Journal of Systems Science: Operations and Logistics, 5(4), 310-326.

Wu, J., Teng, J.-T., \& Skouri, K. (2018b). Optimal inventory policies for deteriorating items with trapezoidaltype demand patterns and maximum lifetimes under upstream and downstream trade credits. Annals of Operations Research, 264, 459-476.

Publisher's Note Springer Nature remains neutral with regard to jurisdictional claims in published maps and institutional affiliations.

\section{Affiliations}

\section{Lin Feng ${ }^{1} \cdot$ Konstantina Skouri ${ }^{2} \cdot$ Wan-Chih Wang ${ }^{3} \cdot$ Jinn-Tsair Teng ${ }^{4,5}$}

Lin Feng

linfeng@swjtu.edu.cn

Konstantina Skouri

kskouri@uoi.gr

Wan-Chih Wang

wanchihwang@mail.hdut.edu.tw

1 School of Economics and Management, Southwest Jiaotong University, Chengdu 610031, China

2 Department of Mathematics, University of Ioannina, 45110 Ioannina, Greece

3 Department of Hospitality Management, HungKuo Delin University of Technology, Qingyun Road, Tucheng District, New Taipei City 236, Taiwan, ROC

4 Department of Management, Marketing, and Professional Sales, The William Paterson University of New Jersey, Wayne, NJ 07470, USA

5 Department of Business Administration, Chaoyang University of Technology, Taichung, Taiwan, ROC 